Sharif University of Technology
Scientia Iranica
Transactions E: Industrial Engineering
hCIENTIA

\title{
Self-efficiency assessment of sustainable dynamic network healthcare service system under uncertainty: Hybrid fuzzy DEA-MCDM method
}

\author{
A. Hasani ${ }^{\mathrm{a}, *}$ and H. Mokhtari ${ }^{\mathrm{b}}$ \\ a. Department of Industrial Engineering and Management, Shahrood University of Technology, Shahrood, 3619995161, Iran. \\ b. Department of Industrial Engineering, Faculty of Engineering, University of Kashan, Kashan, 8731753153, Iran. \\ Received 17 September 2019; received in revised form 29 June 2020; accepted 14 September 2020
}

\author{
KEYWORDS \\ Healthcare \\ management; \\ Sustainable \\ development; \\ Uncertainty; \\ Dynamic; \\ Hybrid assessment \\ method; \\ Hospital network.
}

\begin{abstract}
In this paper, sustainability-related factors involved in the success of healthcare system management including a group of hospitals are considered. A three-pronged approach is adopted based on the internal functions of a hospital which affect such functions as social responsibility and the ones related to the services received from health centers. A novel comprehensive multi-period evaluation of hospital performance is applied to the proposed dynamic network. This hybrid data envelopment analysisbased fuzzy multi-criteria decision-making model incorporates fuzzy Decision Making Trial and Evaluation Laboratory (DEMATEL), and the best-worst method provides a number of useful managerial insights based on a realistic case study from Iran to ensure sustainable management of the healthcare system. Obtained results indicate the important role of considering potential inter-related relations between network nodes to ensure a comprehensive performance assessment of the healthcare service system.
\end{abstract}

(C) 2022 Sharif University of Technology. All rights reserved.

\section{Introduction}

Most healthcare service-providing systems are facing various challenging concerns and new obstacles such as staggering increase in costs, growing number of patients admitted to the hospital, raising healthcare standards, and serious lack of required and skilled numbers of physicians and nurses [1,2]. To efficiently meet the aforementioned challenges, there is a need to evaluate the overall performance of hospitals. In all sectors, especially in healthcare, performance evaluation is im-

\footnotetext{
*. Corresponding author.

E-mail addresses: aa.hasani@shahroodut.ac.ir (A. Hasani); Mokhtari_ie@kashanu.ac.ir (H. Mokhtari)
}

portant for an organization to appropriately compete with the aim of controlling their shortages related to their competitors according to the bounded inputs and desired outputs. To gain more competitive advantages, hospitals should utilize maximum available capacities of resources for achieving staff efficiency, assessing all features of organizational performance, and efficiently responding and adopting decisions according to findings from the business environment. Sustainability factors play a serious role in the long-term achievement of the organization and gaining of competitive advantages; hence, the organization's efficiency evaluation becomes more complicated due to today's social and environmental pressures as well as common financial concerns. Therefore, economic, social, and environmental factors have been concurrently considered in a sustainable development concept [3]. Furthermore, 
governments and various non-governmental institutes have played major roles in driving sustainable development [4]. Therefore, sustainable development issues have received impressive attention so as to meet customers' needs. Organization planning consistent with the key principles of sustainable development ensures stable economic growth and environmental protection. Finally, an organization's reputation will be enhanced through concentration on the corporate social responsibility [5]. It should be noted that hospitals have a key function in amending the public health [6]. Based on the report of the World Health Organization (WHO), the healthy population of each country has a significant impact on national economic growth rate and development [7]. The healthcare service-providing system, especially hospital centers, is one of the key national resources and is considered to be a critical potential for social and economic promotions. In addition, the rate of local employment can be influenced by healthcare system development, such as increase in the number of hospitals. Therefore, the society can gain advantages if hospitals succeed in providing high-quality health services and implementing integrated sustainability approaches [8]. In this way, simultaneously various outcomes such as economic persistence, operating efficiency, organizational resource management, and corporate social responsibility will be achievable [9]. These results indicate the importance of making hospitals sustainable. Hospitals need appropriate access to resources in not only physical and non-physical respects but also social one. Data Envelopment Analysis (DEA) among all the existing methods to assess the efficiency has been noted and proven to be an effective approach in recent years [10,11]. DEA is a nonparametric method with no frontier in the efficiency boundary that evaluates the relative efficiency of a group of observed homogenous Decision-Making Units (DMUs) which may change over time in terms of comparable objectives and variables that can be grouped into two separate groups of inputs and outputs [10].

Despite the importance of this issue, only a few studies have been done on sustainability issues and the actual execution is still not satisfactory. Healthcare service network has a profound impact on Iran economy and represents one of the major grounds for boosting the economic growth [12]. There is an essential need for further investigation in this domain [13]. Enhancing the sustainability of hospitals ensures the future of health planning [14]. Therefore, making Iran's healthcare network sustainable is essential, too. It is obvious that fundamental assessment approaches to promoting sustainability of each node of healthcare network can improve its economic, social, and environmental conditions. Thus, the main objective of this study is to propose a comprehensive model for the efficiency evaluation of the dynamic performance of hospitals with multidimensional functions based on the key principles of sustainable development. The network of hospitals includes three main nodes: hospital, community, and patient. For this purpose, the interval type2 fuzzy dynamic network DEA is applied to conduct the aforementioned analysis for healthcare network sustainability and to investigate the efficiency of the entire healthcare management system on diverse time scales. To determine total efficiency, the proposed assessment model considers three related subsystems along with the internal functions of the healthcare network, its impact on community as a whole, and its straight impact on patients. Efficiency score calculations can be conducted on various time scales. This timedependent analysis facilitates performance evaluation of healthcare networks on specific time scales including disaster and normal times. Uncertainties in input and output data are handled using the interval type-2 fuzzy technique incorporated in the dynamic network DEA, thus making it possible to consider uncertainty in the entire process of analysis and to improve the accuracy of the obtained results.

This paper is organized as follows. Section 2 discusses the related literature. Section 3 formulates the proposed network dynamic efficiency assessment model, which is defined and established mathematically. Section 4 describes a case study analysis and presents some results and managerial insights. Finally, Section 5 concludes the paper.

\section{Literature review}

In recent years, numerous research studies have assessed the healthcare and primary care facilities from various angles [15]. Healthcare systems are evolving towards a complex network of interrelated services as a result of growing expenses as well as expectations of patients for high-level services. Therefore, there is a strict need to appropriate management methods and techniques to enhance the efficiency of healthcare systems, particularly in emerging economies with severe resource constraints [16]. Among the many approaches proposed for the hospital efficiency assessment, DEA has been the most popular one where complex processes with multiple inputs and outputs are regarded without requirement for any prior assumptions or suppositions about the functional form of the considered process $[11,16]$. The DEA method is capable of considering several vital and relevant outputs and inputs, which are added to the effective evaluation, and determining unit efficiency as well as ranking them $[17,18]$. DEA has been widely applied in the previous research for the purpose of efficiency assessment of hospitals. Various parameters are regarded as input factors including numbers of labor and beds as well 
as costs. Some of the common output factors are 'the number of patients referred for diagnosis and treatment', 'number of beds being occupied', 'training of the medical staff', 'incomes', and other similar cases. Bhat et al. [19] investigated the hospital efficiency of district-level government-funded hospitals and grantin-aid hospitals in Gujarat using the DEA approach in terms of their technical and allocative efficiency. Ozgen and Ozcan [20] conducted a longitudinal analysis of efficiency in multiple output dialysis markets using the DEA-based Malmquist index in the United States from 1994-2000. Kontodimopoulos and Niakas [21] assessed the total factor productivity of dialysis facilities in Greece over a 12-year period from 1993-2004 using nationally representative panel data with hybrid DEA and Malmquist productivity indices by considering technical efficiency as well as technological changes. $\mathrm{Ng}[22,23]$ proposed an efficiency assessment model based on DEA technique to evaluate the productivity of hospitals in China and investigate the relationship between regional development and hospital efficiencies. $\mathrm{Li}$ et al. [24] examined the productivity status of public hospitals in Beijing and analyzed the created productivity growth in specific periods. Du et al. [25] proposed a super-efficient assessment model based on the DEA, which considers both the quantity and the quality of the output, to assess hospital efficiency in Pennsylvania. Feng et al. [26] studied the hospital efficiency assessment problem by considering differences between geographic location (i.e., geographic location and ownership) and ownership (i.e., public and private hospitals) status. Various studies have assessed the efficiency of hospitals in terms of ownership types such as public, private, and non-profit hospitals [27]. Arya and Yadav [27] proposed a novel intuitionistic fuzzy slack-based measure model to examine the efficiency of DMUs and intuitionistic fuzzy super efficiency slackbased measure for a healthcare sector. In many real cases of the decision-making environment, we have only limited information about the distribution of the considered uncertain parameters. In this situation, there is no appropriate qualitative or quantitative explanation on behavior of the uncertain parameter. Therefore, because of the limited historical data to fit appropriate probability distribution for uncertain parameters in many real-world applications as well as the inherent modeling and/or computational complexities of stochastic programming models, applications of the stochastic programming models are restricted. In these situations, fuzzy programming and robust optimization approaches could be adopted for handling uncertainty of parameters. When an interpretation of the behavior of uncertain parameter distribution within a specific range is proposed, a fuzzy programming approach is applied to handle uncertainty [28]. A type2 fuzzy set is described by a fuzzy membership function, unlike a type-1 fuzzy set. In the type- 1 fuzzy set, the membership degree is considered a crisp number. Therefore, a type-2 fuzzy set is capable to model the uncertainties directly since it offers extra degrees of freedom [29]. The consequential sets of the if-then rules for a type-2 fuzzy logic system are of type 2. type-2 fuzzy logic systems have been used in many real studies in recent years [30].

Another important concern is the resource allocation problem with an noticeable impact on hospital success performance $[31,32]$. The DEA is capable to be used as a resource allocation method besides other common methods such as dynamic programming, goal programming, and simulation [33,34]. Khushalani and Ozcan [35] proposed a DEA model for hospital subdivisions including medical and surgical care efficiency assessment. Omrani et al. [36] proposed a DEA model based on the clustering method for DMUs under uncertainty to assess the total performance of healthcare centers. Motevali Haghighi and Torabi [37] proposed a hybrid sustainability-resilience framework for Hospital Information System (HIS) assessment using the Best-Worst Method (BWM) for determining the importance weight of each assessment indicator and the DEA for performance evaluation at different hospital departments. Zare et al. [38] developed a hybrid DEAGame theory framework to analyze the total performance of healthcare centers in Iran. Rouyendegh et al. [39] proposed a DEA that incorporates an Analytic Hierarchy Process (AHP) to improve the total business performance in the healthcare system network. Ghahremanloo et al. [40] proposed a new approach to hospital efficiency assessment to simultaneously examine the efficiency, effectiveness, and applicability of an extended DEA model.

It should be mentioned that only the values of primary inputs and outputs of the healthcare service network are determined by the aforementioned traditional DEA as an assessment technique. Therefore, intermediate activities are considered as a black box in the process assessment. However, these activities could play an important role in transforming the determined inputs to desired outputs and creating desirable values in such a complex healthcare network. For tackling this challenge, no study has been conducted on the network DEA model for the healthcare system which considered the intermediate variables as the relationship between variables through linkage variables. There are two common approaches to handling the analysis of the network process by DEA including radian and SlacksBased Measure (SBM) network approaches [41,42]. This study takes into account the interrelated role of intermediate activities by determining specific nodes such as hospital, community, and patients in the healthcare service network. Therefore, wide ranges of activities and interactions yielding potential feedback 
are considered in the proposed healthcare service network.

Another challenge of efficiency assessment of complex systems is considering the dynamic nature of the assessment environment. To increase the effectiveness of the assessment process, there is a strict need to consider the impacts of a prior performance of a group of units on the evaluation of their present performance. To handle the aforementioned challenge, the dynamic network DEA approach is adopted, which considers the next impact of decision variable on the process performance using carry-over variables (i.e., variables link different networks on each time scale) [43-45]. For instance, a positive attitude of the organization resulting from various factors like corporate reputation could lead to a positive word of mouth, which ultimately comes back to cause further changes in the corporate reputation (i.e., a reinforcing loop). Finally, the sensitivity of a community to corporate mistakes will be reduced upon growth in company reputation. These aforementioned merits encourage companies to develop their popularity via various approaches including the efforts to attend to environmental and social responsibility concerns, which are really important for the community [46,47]. The interested readers are referred to the study of Cantor and Poh [15] for further information about the DEA as a performance evaluation technique in efficiency measurement of healthcare systems. Despite all these studies, there is still a need to develop more powerful and efficient comprehensive assessment models for evaluating the efficiency of sustainable healthcare service-providing system. The main contribution of the present study is to propose a comprehensive efficiency assessment model for a sustainable healthcare system by considering the network assessment model, dynamics of decision-making environment, and uncertainty of assessment variables. For this purpose, a new hybrid fuzzy DEA-MCDM technique is proposed (see Table 1).

\section{Problem statement}

In this study, the main objective is to evaluate hospitals' total efficiency in terms of their policies and initiatives in line with the key principles of sustainable development. The framework of the proposed hybrid efficiency assessment is depicted in Figure 1. The proposed assessment model is developed based on the network DEA approach (see Figure 2). The considered nodes in the proposed network include hospital, community, and patients. Since a hospital could not remain isolated from other sections of its related society and has an interaction with them, it is not sufficient to merely consider its inter-organizational functions or financial performance measures such as achieved revenue in determining the efficiency of the hospital. The aim of the organization's social responsibility is to

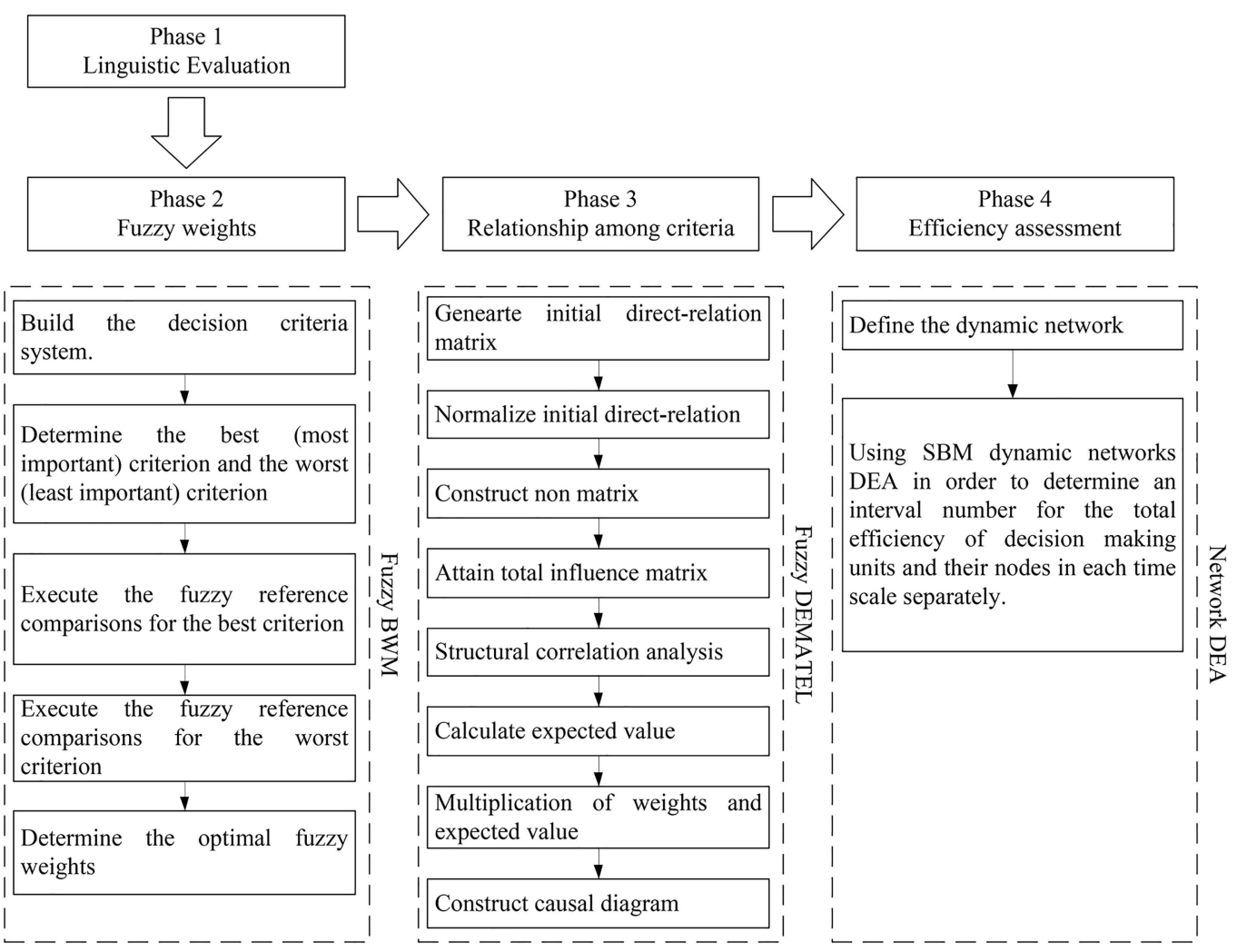

Figure 1. The proposed hybrid method for efficiency assessment. 


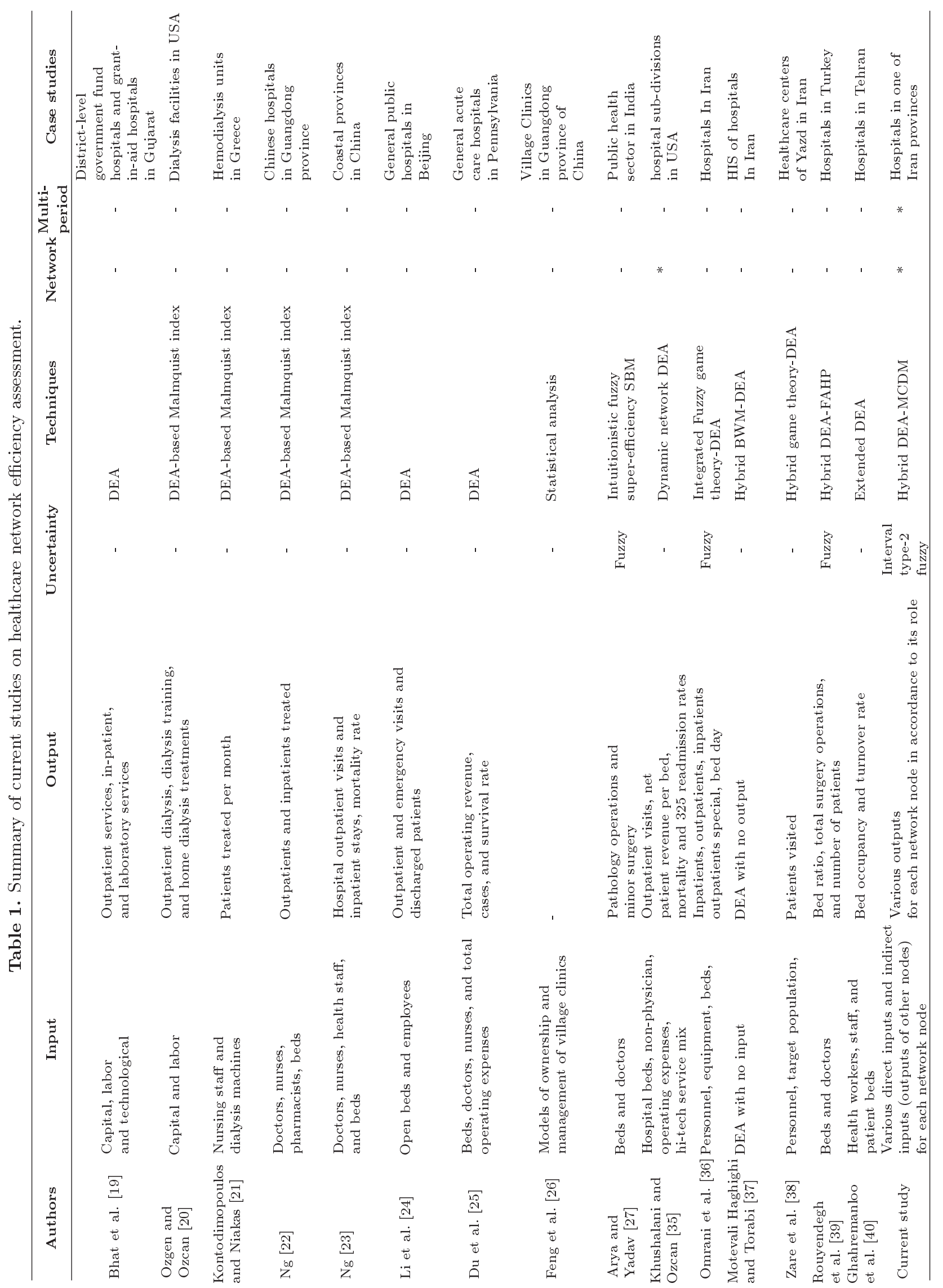




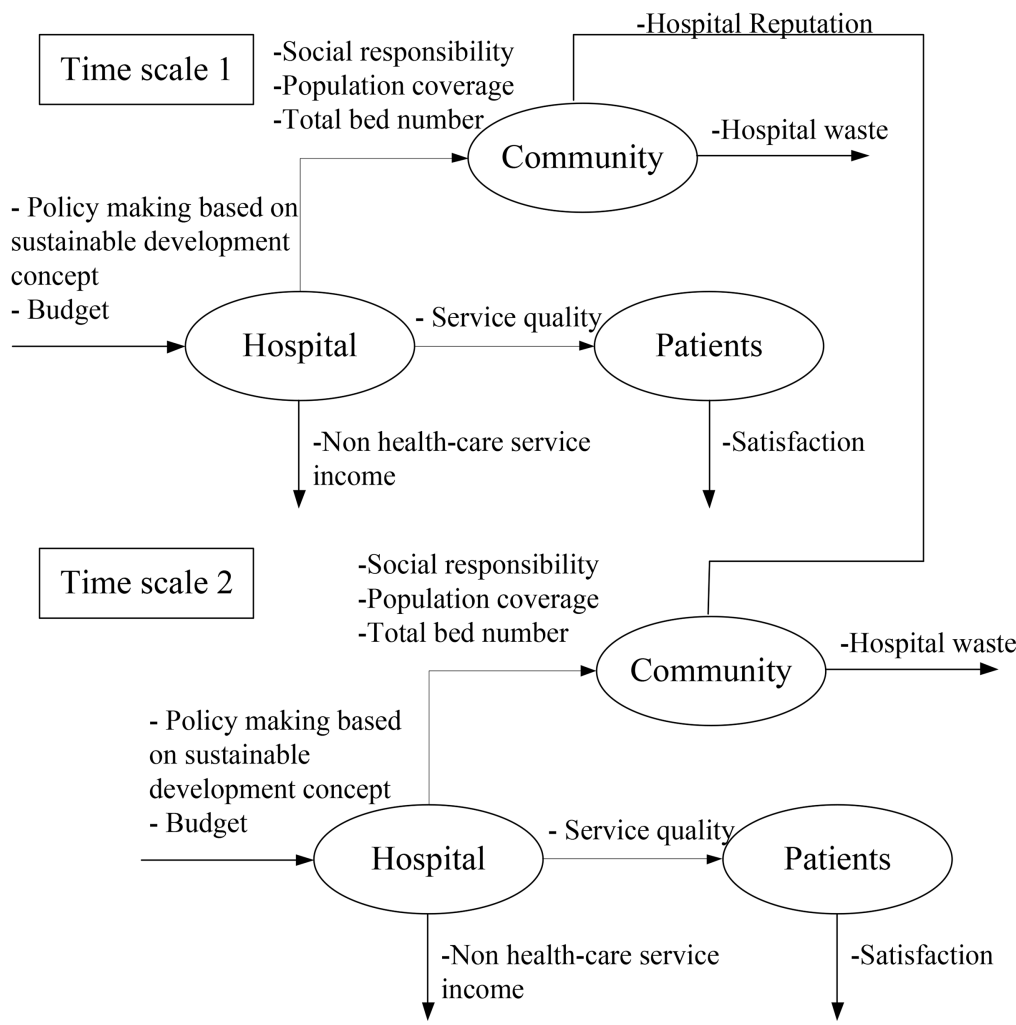

Figure 2. Network DEA for the hospital efficiency assessment.

admit responsibility for the organization's activities and reinforce positive feedback from conducted efforts for the environment, consumers, employees, communities, and all the other relevant stakeholders at the society level. Therefore, a wide range of industries with diverse functional levels should consider environmental and social responsibilities in order to maintain appropriate consistency as well as the progress of their business.

Reliance on financial objectives alone cannot ensure the survival of a hospital as one of the most important healthcare facilities. Regardless of this responsibility, an organization could not gain a fine reputation and corporate sustainability could not be guaranteed without a good reputation. In this study, the hospital's acts in contradiction to the community expectations are so important and regarded for proper total efficiency assessment of hospitals. In addition, the activities of the hospital managers should be taken into account to enhance the quality of healthcare services according to patients' needs. Furthermore, these attempts should be made such that patients would recognize them and find them rewarding. This recognition by patients will have a significant impact on their satisfaction. Otherwise, one can argue that the resources of the hospital are wasted. The effectiveness of the internal functions as a standalone parameter cannot be adequate. Dissatisfaction of patients and the community threatens hospital sustainability during the planning horizon. Consequently, there is a strict need to define hospital efficiency, as a whole system, on different levels as subsystems of hospital, community, and patients. Each node of the considered network can have a specific weight, which represents the importance of its activities in determining efficiency. In this study, these weights are determined based on the hybrid decision-making method which incorporates an interval type-2 fuzzy Decision Making Trial and Evaluation Laboratory (DEMATEL) and BWM techniques based on the experts' opinions. The main steps of the applied fuzzy DEMATEL are summarized as follows:

- Step 1-1: Collect data by means of group experts or Decision-Makers (DMs). They are asked to fill the ratio from " 0 " to " 4 ", from no influence to very high influence;

- Step 1-2: Generate the initial direct-relation matrix by aggregating the DMs' opinions;

- Step 1-3: Calculate the normalized initial directrelation matrix;

- Step 1-4: Construct $n \times n$ matrix to fit the identified matrix;

- Step 1-5: Attain the total-influence matrix, $T$;

- Step 1-6: Conduct structural correlation analysis;

- Step 1-7: Calculate the expected value, $E(W)$, to convert the interval type-2 fuzzy set into crisp numbers; 
- Step 1-8: Construct a causal diagram based on $E$ $(D i+R i)$ and $E(D i+s)$.

In addition, the main steps of the applied fuzzy BWM method are summarized as follows:

- Step 2-1: Design a decision criteria system that is comprised of decision criteria (i.e., $n$ decision criteria $C_{1}, C_{2}, \ldots, C_{n}$ ), which is very important for performing the alternatives evaluation reasonably. The values of this matrix present the performance of different alternatives;

- Step 2-2: Determine the best $\left(C_{B}\right)$ and worst $\left(C_{w}\right)$ criteria based on DMs' opinions;

- Step 2-3: Execute fuzzy reference comparisons for the best and worst criteria. First, a pairwise comparison $\hat{a}_{i j}$ is made for all the considered criteria in case $i$ is the best element and $c_{i}$ is the best criterion $C_{B}$. Second, a pairwise comparison $\hat{a}_{i j}$ is made for all the considered criteria in case $j$ is the worst element and $c_{i}$ is the worst criterion $C_{W}$. These comparisons including fuzzy best-toother and other-to-worst vectors are made using linguistic variables. Then, they are transformed into triangular fuzzy numbers according to the considered transformation rules;

- Step 2-4: Determine the optimal fuzzy weights using the constrained optimization problem $\left(\hat{w}_{1}^{*}, \hat{w}_{2}^{*}, \ldots, \hat{w}_{n}^{*}\right)$.

Through the assessment process, some variable values are calculated based on the patients' opinions by using a standard questionnaire (see Figures A.1 and A.2 as well as Table A.1 in the Appendix). The questionnaire was validated and found reliable based on the experts' opinions and Cronbach's alpha $=$ 0.80 , respectively. To consider linguistic variables and descriptive answers of respondents, the fuzzy approach is used based on the concept of type-2 fuzzy sets as an extension of the concept of the type-1 fuzzy set [48]. Finally, efficiency assessment is done using the proposed SBM dynamic network DEA (see Subsection 3.1).

\subsection{Model development and description}

In this section, the proposed SBM dynamic network DEA is introduced. More levels of uncertainty could be considered in the assessment process using type2 fuzzy sets compared with general type-1 fuzzy sets. Interval type-2 fuzzy numbers handle the uncertainty of membership function, as shown in Eq. (1) [49]. A crisp number including $C$ could be converted into an interval type-2 fuzzy number as follows: (c, c, c, c; 1, 1) and $(c, c, c, c ; 0.9,0.9)[50]$. Considering " $I F_{1}$ " and " $I F_{2}$ " as two trapezoidal interval type-2 fuzzy numbers as follows (see Eqs. (1) and (2)). The mean of patients' opinions of each dimension of the considered variables is calculated by Eq. (2). Index " $T_{n}$ " represents the total number of patients, as members of research society, at each hospital. The mean of the obtained patients' opinions about each research question is calculated using Eq. (2):

$$
\begin{aligned}
I F_{1}= & \left(I F_{1}^{U}, I F_{1}{ }^{L}\right) \\
= & \left(i f_{11}^{U}, i f_{12}^{U}, i f_{13}^{U}, i f_{14}^{U} ; H O_{1}\left(I F_{1}{ }^{U}\right)\right), \\
& \left(i f_{11}^{L}, i f_{12}^{L}, i f_{13}^{L}, i f_{14}^{L} ; H O_{1}\left(I F_{1}{ }^{L}\right), H O_{1}\left(I F_{1}{ }^{L}\right)\right), \\
I F_{1}= & \left(I F_{2}^{U}, I F_{2}{ }^{L}\right)= \\
& \left(i f_{21}^{U}, i f_{22}^{U}, i f_{23}^{U}, i f_{24}^{U} ; H O_{1}\left(I F_{2}{ }^{U}\right)\right), \\
& \left(i f_{21}^{L}, i f_{22}^{L}, i f_{23}^{L}, i f_{24}^{L} ; H O_{1}\left(I F_{2}{ }^{L}\right), H O_{1}\left(I F_{2}{ }^{L}\right)\right) .
\end{aligned}
$$

The lower and upper bounds of each research variable in the form of fuzzy set number are determined according to the patients' statements using Eqs. (3) and (4), respectively (Eqs. (3) and (4) are shown in Box I). By using the interval type-2 fuzzy numbers, variable values in the proposed network are determined (Eqs. (5) and (6) are shown in Box II). In addition, Eqs. (7) and (8) determine the upper and lower bounds of the values of the considered variables. Finally, the SBM model incorporated into the dynamic networks DEA calculates the total efficiency of DMUs and their nodes in each period, separately. These lower and upper bounds are taken so as to set the lower and upper bounds of the considered hospitals' efficiencies.

$$
\begin{aligned}
M O_{*}\left(I F_{1}\right)= & \frac{1}{6}\left(i f_{15}^{U b}+2 i f_{16}^{U b}\right) H O_{1}^{U b} \\
& +\frac{1}{6}\left(i f_{11}^{L b}+2 i f_{12}^{L b}\right) H O_{1}^{L b}, \\
M O_{*}\left(I F_{1}\right)= & \frac{1}{6}\left(i f_{18}^{U b}+2 i f_{17}^{U b}\right) H O_{2}^{U b} \\
& +\frac{1}{6}\left(i f_{14}^{L b}+2 i f_{13}^{L b}\right) H O_{2}^{L b} .
\end{aligned}
$$

Specific constraints are regarded for each input (in), output (ou), link (li), and carry-over (co) of all the nodes in the proposed network to determine the upper bound efficiency. In the proposed network, there are three types of nodes: hospital, community, and patients. The desirable or undesirable inputs and outputs of each node in each time period are determined using Eqs. (9) and (10), respectively. $i n_{j}^{L t}$ and $o u_{j}^{u t}$ represent the input and output of each node, respectively. $s i_{q k}{ }^{t-i n p u t}$ and $s i_{q k}{ }^{t-o u t p u t}$ indicate the link as input and output of each node, respectively. 


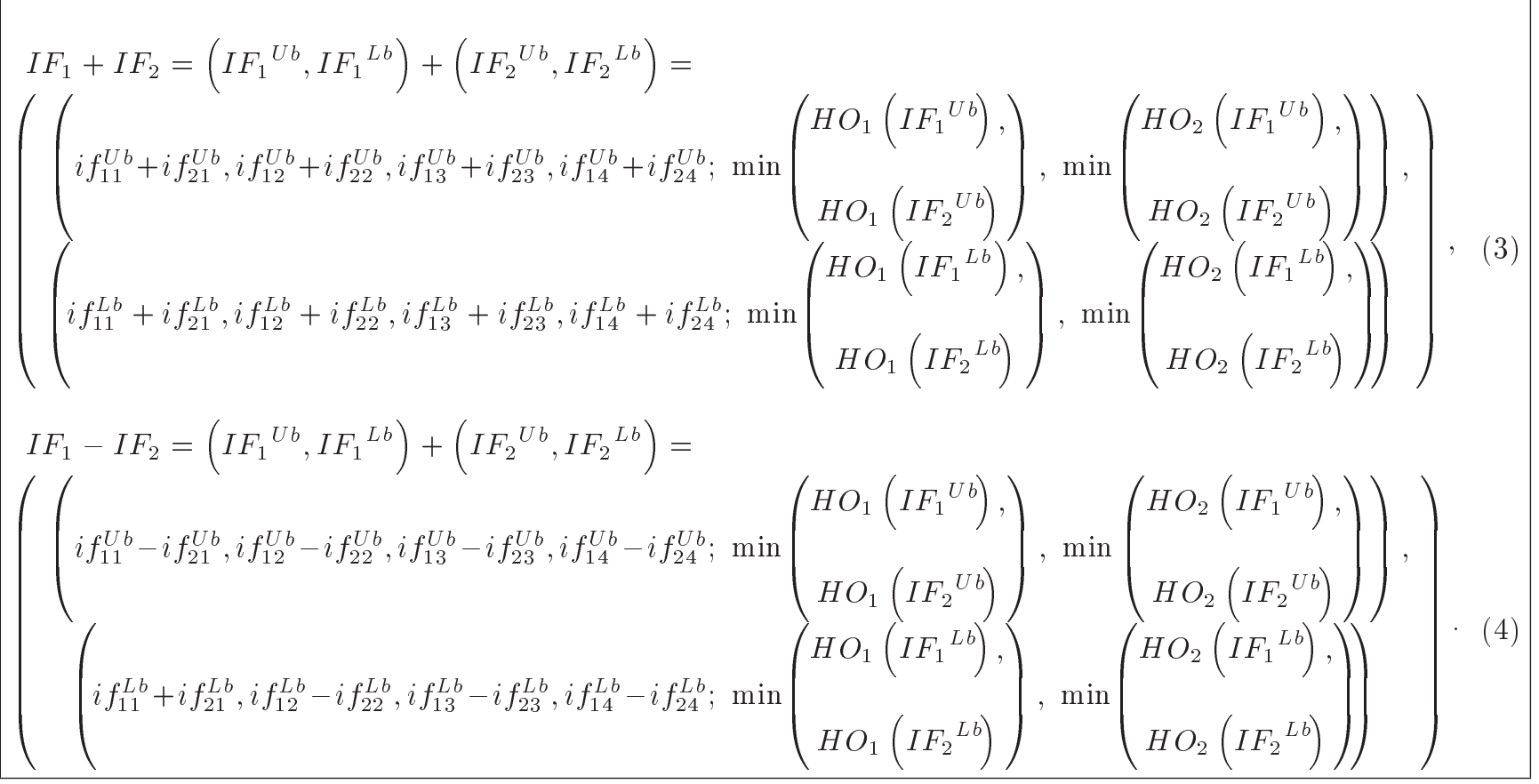

Box I

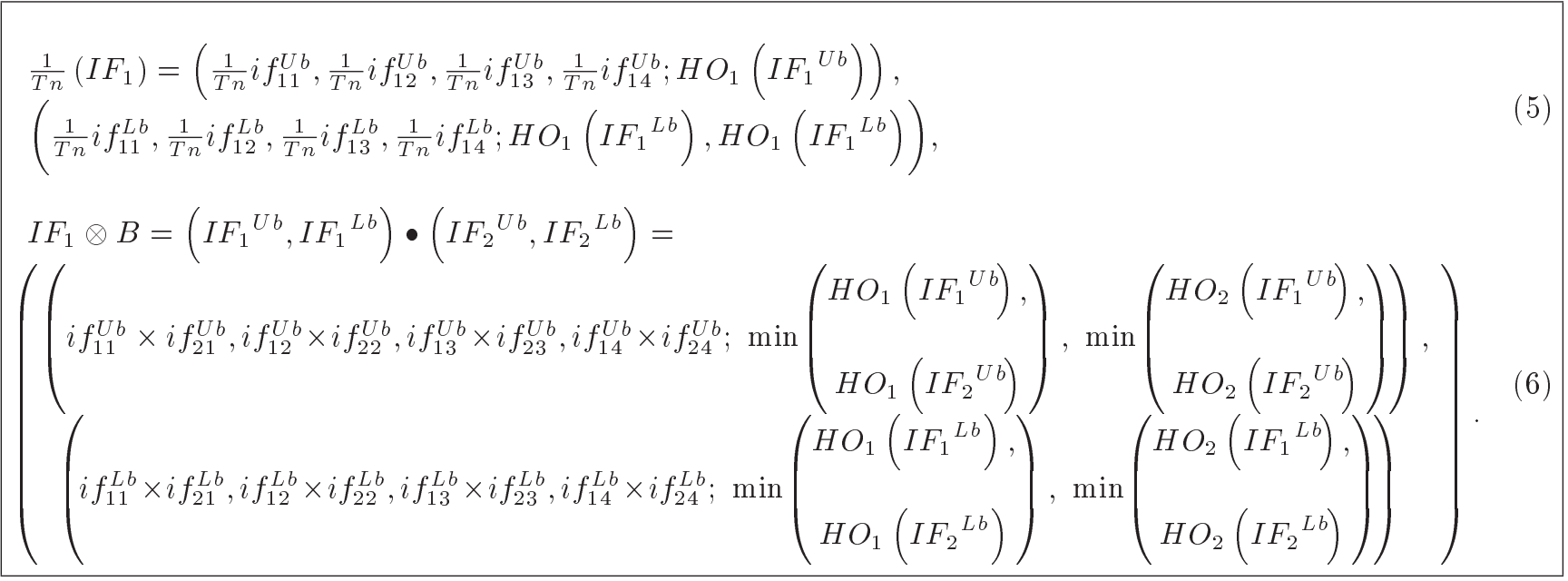

Box II

$$
\begin{aligned}
& \sum_{j=1}^{n_{D M U}} i n_{j}^{L t} \cdot \mu_{q j}^{t}+s i_{q k}^{t-i n p u t}=i n_{0}^{L t} \\
& \forall t, q=1,2,3, \quad k=1, \ldots, n_{\text {inputs }}
\end{aligned}
$$

$$
\sum_{j=1}^{n_{D M U}} o u_{j}^{U t} \mu_{q j}^{t}+s i_{q m}^{t-o u t p u t}=o u_{0}^{U t}
$$$$
\forall t, q=1,2,3, \quad m=1, \ldots, n_{\text {output }} .
$$

It should be mentioned that all the relations and carry-overs as outputs of the first node are considered the input of the second node. The desirability of each node is incorporated by Eqs. (11) and (12). Continuity of the link connection among the related nodes is presented through Eq. (13). $\mu_{q j}^{t}$ represents the coefficient of the Variable Return to Scale (VRS) model for each node. Eq. (14) considers a similar approach to carry-overs. The proposed model is applied in the VRS by using Eq. (15). Eq. (16) indicates that variables $\lambda$ and $s$ are positive.

$$
\sum_{j=1}^{n_{D M U}} l i_{j}^{(\text {output }) U b} \cdot \mu_{i f_{2}, j}^{t}=\sum_{j=1}^{n_{D M U}} l i_{j}^{(\text {input }) L b} \cdot \mu_{i f_{1}, j}^{t}
$$

$\forall t, D M U$ 


$$
\begin{aligned}
& \sum_{j=1}^{n_{D M U}} c o_{j}^{(\text {output }) U b} \cdot \mu_{i f_{2}, j}^{t}=\sum_{j=1}^{n_{D M U}} c o_{j}^{(\text {input }) L b} \cdot \mu_{i f_{1}, j}^{t+1} \\
& \forall t, D M U \\
& \sum_{j} \mu_{q j}^{t}=1 \quad \forall q, t \\
& \forall s, \lambda \geq 0 .
\end{aligned}
$$

Eqs. (15) and (16) define auxiliary variables for Eqs. (17)-(19). Eq. (19) shows the objective function for calculating the upper bound of total efficiency of the health service-providing network in the assessment period. Eq. (18) determines the upper bound of each node efficiency in each period. Eq. (19) calculates the upper bound of each node efficiency in the assessment period. It should be mentioned that the lower bound of the considered efficiency measures is defined in the same way.

$$
\begin{aligned}
& \mu_{\text {input }}^{t q}=\frac{1}{\sum_{\begin{array}{c}
c=i n p u t s, \\
\text { ink-as-input, } \\
\text { carryover-as-input }
\end{array}} \eta_{c}}\left(\sum_{k} \frac{s i_{q k}^{t-i n p u t}}{i n_{0}^{L t}}\right. \\
& \left.+\sum_{r} \frac{s i_{q r}^{t-i n p u t}}{z_{0}^{L t}}+\sum_{m} \frac{s i_{q m}^{(t, t+1)-i n p u t}}{z_{0}^{(t, t+1) U}}\right), \\
& \mu_{\text {output }}^{\text {tq }}=\frac{1}{\sum_{\begin{array}{c}
\text { c=outputs, } \\
\text { ink-as-output, } \\
\text { carryover-as-output }
\end{array}} \eta_{c}}\left(\sum_{m} \frac{s i_{q m}^{t-o u t p u t}}{o u_{0}^{U t}}\right. \\
& \left.+\sum_{r} \frac{s i_{q r}^{t-\text { output }}}{z_{0}^{U t}}+\sum_{m} \frac{s i_{q m}^{(t, t+1)-o u t p u t}}{z_{0}^{(t, t+1) U}}\right) \\
& \mu_{0}^{U}=\min \left[\frac{\sum_{t=1}^{2} w^{t}\left[\sum_{q=1}^{3} w^{q}\left[1+\mu_{\text {input }}^{t q}\right]\right]}{\sum_{t=1}^{2} w^{t}\left[\sum_{q=1}^{3} w^{q}\left[1+\mu_{\text {output }}^{t q}\right]\right]}\right] \\
& \pi_{0}^{U q}=\min \left[\frac{1+\mu_{\text {input }}^{t q}}{1+\mu_{\text {output }}^{\text {tq }}}\right] \text {, } \\
& \phi_{0}^{U q}=\min \left[\frac{\sum_{t=1}^{2} w^{t}\left[1+\mu_{\text {input }}^{t q}\right]}{\sum_{t=1}^{2} w^{t}\left[1+\mu_{\text {output }}^{t q}\right]}\right] .
\end{aligned}
$$

Eqs. (20) and (21) consider the desired values of inputs and output variables. As mentioned before, the links and carry-overs should be taken as input of the second node and output of the first node in accordance with their desirability for each related node. Similarly, equations of undesirable inputs are better to be defined as the equations of desirable outputs.

$$
\begin{gathered}
\sum_{j=1}^{n_{D M U}} i n_{j}^{L t} \cdot \mu_{q j}^{t}+s i_{q k}^{t-i n p u t}=i n_{0}^{U t} \\
\forall t, q=1,2,3 \quad k=1, \ldots, n_{\text {inputs }}, \\
\sum_{j=1}^{n_{D M U}} o u_{j}^{U t} \cdot \mu \lim _{\delta x \rightarrow 0_{q j}}^{t}-s i_{q m}^{t-\text { output }}=o u_{0}^{L t} \\
\forall t, q=1,2,3 \quad k=1, \ldots, n_{\text {output }} .
\end{gathered}
$$

In addition, Eqs. (22) and (23) display the connection between the links and carry-overs in the proposed dynamic DEA network. Finally, Eqs. (24) and (25) are added to the proposed efficiency assessment model, similar to previous cases:

$$
\begin{gathered}
\sum_{j=1}^{n_{D M U}} l i_{j}^{(\text {output }) U} \cdot \mu_{b j}^{t}=\sum_{j=1}^{n_{D M U}} l i_{j}^{(\text {input }) U} \cdot \mu_{a j}^{t} \\
\forall t, D M U, \\
\sum_{j=1}^{n_{D M U}} c o_{j}^{(\text {output }) U} \cdot \mu_{b j}^{t}=\sum_{j=1}^{n_{D M U}} c o_{j}^{(\text {input }) U} \cdot \mu_{a j}^{t+1}
\end{gathered}
$$

$\forall t, D M U$

$$
\begin{aligned}
& \sum_{j=1}^{10} \mu_{q j}^{t}=1 \quad \forall q, t, \\
& \forall s, \lambda \geq 0 .
\end{aligned}
$$

Eqs. (26) and (27) define auxiliary variables for Eqs. (28)-(30). Eqs. (28)-(30) present the three considered objective functions of the proposed model. Eq. (30) shows the lower bound of total efficiency. Eq. (31) illustrates the lower bound of node efficiency in each period. Eq. (32) presents the lower bound of each node efficiency during the assessment period:

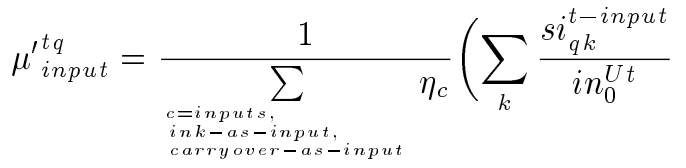

$$
\begin{aligned}
& \left.+\sum_{r} \frac{s i_{q r}^{t-i n p u t}}{z_{0}^{U t}}+\sum_{n} \frac{s i_{q n}^{(t, t+1)-i n p u t}}{z_{0}^{(t, t+1) U}}\right), \\
& \mu_{\text {output }}^{\prime t q}=\frac{1}{\sum_{\substack{\text { c=outputs, } \\
\text { ink-as-output, } \\
\text { carryover-as-output }}} \eta_{c}}\left(\sum_{m} \frac{s i_{q m}^{t-\text { output }}}{o u_{0}^{L t}}\right.
\end{aligned}
$$




$$
\begin{gathered}
\left.+\sum_{r} \frac{s i_{q r}^{t-\text { output }}}{z_{0}^{L t}}+\sum_{n} \frac{s i_{q n}^{(t, t+1) \text { output }}}{z_{0}^{(t, t+1) L}}\right), \\
\mu_{0}^{L}=\min \left[\frac{\sum_{t=1}^{2} w^{t}\left[\sum_{q=1}^{3} w^{q}\left[1+\mu_{\text {input }}^{\prime t q}\right]\right]}{\sum_{t=1}^{2} w^{t}\left[\sum_{q=1}^{3} w^{q}\left[1+\mu_{\text {output }}^{\prime t q}\right]\right]}\right], \\
\pi_{0}^{L q}=\min \left[\frac{1+\mu_{\text {input }}^{\prime t q}}{\left.1+\mu_{\text {output }}^{\prime t q}\right]}\right] \\
\phi_{0}^{L q}=\min \left[\frac{\sum_{t=1}^{2} w^{t} \cdot\left[1+\mu_{\text {input }}^{\prime t q}\right]}{\sum_{t=1}^{2} w^{t} \cdot\left[1+\mu_{\text {output }}^{\prime t q}\right]}\right] .
\end{gathered}
$$

By using Eq. (31), the possibility degrees of the realized preferences about the hospitals' efficiencies can be determined considering the upper and lower bounds of their efficiencies.

$p\left(E_{2} \succ E_{1}\right)=$

$\frac{\max \left(0,\left(\left(\bar{E}_{2}-E_{2}\right)+\left(\bar{E}_{1}-E_{1}\right)-\max \left(0,\left(\bar{E}_{1}-E_{2}\right)\right)\right)\right)}{\left(\bar{E}_{2}-E_{2}\right)+\left(\bar{E}_{1}-E_{1}\right)}$.

Eq. (32) shows the matrix of possibility degrees of preferences for hospitals. Each row of the proposed possibility degree matrix presents the possible degrees of preferences of a hospital compared to other ones. This matrix contains a set of values with degrees equal to or greater than 0.5 in one row. Therefore, the associated hospital has been ranked first among the others. Other hospitals are evaluated after removing the associated row and column of the selected hospital in the previous step [48].

$$
P=\left(\begin{array}{lll}
P\left(E_{1} \succ E_{1}\right) & \ldots & P\left(E_{1} \succ E_{28}\right) \\
\vdots & \ldots & \vdots \\
P\left(E_{28} \succ E_{1}\right) & \ldots & P\left(E_{28} \succ E_{28}\right)
\end{array}\right)
$$

\section{Experimental results and managerial insights}

\subsection{Assessment of network nodes priorities}

Each node as a key component of the considered network has a specific weight and the importance of node activities in efficiency assessment. The weights of network nodes are calculated using a hybrid method that incorporates the interval type-2 fuzzy DEMATEL and BWM based on the experts' opinions. DEMATEL is used to investigate the complex and intertwined problematic group that has been extensively known as one of the best methods to explain the causal relationship between the assessment measures [51]. DEMATEL is proposed to investigate and develop the causal relationship between evaluation measures or to derive interrelationship between factors [52]. The BWM is based on an organized pairwise comparison of the decision factors which are applied as input values to a decision-making problem [53]. The obtained outcomes are the weights of the considered factors. The noticeable attribute of the BWM is that it uses an organized approach to making pairwise comparisons, leading to consistent outcomes [53]. Experts are particularly selected among the studied hospitals' managers at various organizational levels. Therefore, 105 experts are utilized to assess the significance of hospital, community, and patient nodes. For defuzzification of the obtained fuzzy results, a common method called Converting Fuzzy data into Crisp Scores (CFCS) is applied [54]. The determined weights of hospital, community, and patient are $0.516,0.301$, and 0.183, respectively. The results of the applied interval type- 2 fuzzy DEMATEL and BWM are presented in Figure 3 and Table 2, respectively.

The final weights of the timescale 1 (New Year holiday) and timescale 2 (normal time) are considered as 0.43 and 0.57 , respectively, based on experts' suggestions.

\subsection{Network efficiency assessment}

To assess the efficiency of the hospital's performance by considering the sustainable development principles, the SBM dynamic network DEA inspired by the model,

Table 2. Preference of the best and worst criteria in comparison to other criteria.

\begin{tabular}{lc}
\hline & Best node (hospital node) \\
\hline Hospital node & $(0,0.111,0.111,0.092 ; 1,1),(0,0.111,111,0.061 ; 0.9,0.9)$ \\
Patient node & $(0.59,0.48,0.48,0.47 ; 1,1),(0.55,0.48,0.48,0.49 ; 0.9,0.9)$ \\
Community node & $(0.52,0.41,0.41,0.44 ; 1,1),(0.53,0.41,0.41,0.46 ; 0.9,0.9)$ \\
\hline & Worst node $($ community node $)$ \\
\hline Hospital node & $(0.97,0.87,0.87,0.80 ; 1,1),(0.93,0.87,0.87,0.85 ; 0.9,0.9)$ \\
Patient node & $(0.1,0.14,0.14,0.19 ; 1,1),(0.12,0.14,0.14,0.19 ; 0.9,0.9)$ \\
Community node & $(0,0.06,0.06,0.08 ; 1,1),(0,0.06,0.06,0.03 ; 0.9,0.9)$ \\
\hline
\end{tabular}




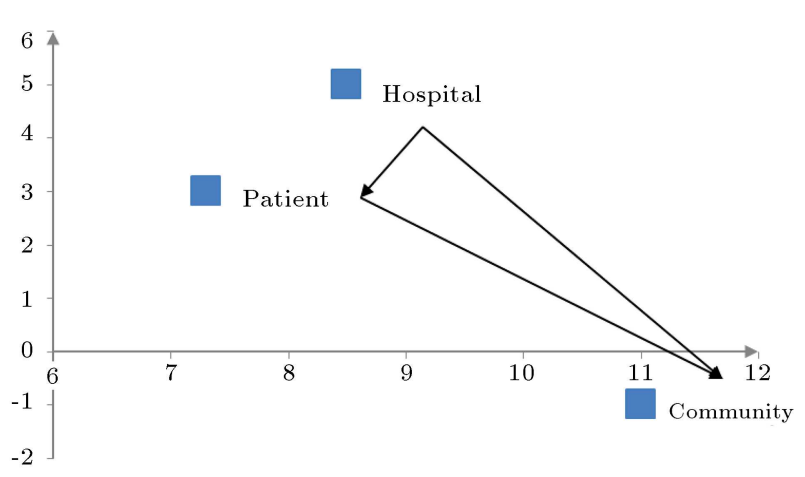

Figure 3. Cartesian coordinate system of the interval type-2 fuzzy DEMATEL output for the main criteria.

which was initially proposed by Tone and Tsutsui [42], is applied. The proposed model is a dynamic DEA model with the network structure as a composition of the dynamic SBM and the network SBM. This model can investigate the total efficiency over the planning period, dynamic change of efficiency during the planning period, and dynamic change of divisional efficiency. By using the SBM (i.e., non-radial), it is assumed that there is no proportional reduction as well as growth in the value of assessment measures. The VRS is a type of the frontier scale used in the DEA methods. The VRS helps estimate efficiencies, that is, whether an increase or decrease in inputs or output values does not lead to a proportional variation in values of outputs or inputs, respectively. Given that production balance is not granted to constituents of social behavior such as service receipt satisfaction by patients, the mentioned approach is important. For instance, it was observed that the enhancement of service quality level would not make a significant change in the satisfaction of patients. In addition, in terms of the considered network, the non-radial approach differentiates the efficient nodes of the network from inefficient ones much better than the radial model. Besides, estimation of hospitals' efficiency in each time period indicates the performance of the considered node more clearly. Therefore, the final efficiency examination has been applied for the last two six-months to facilitate investigating the status of the studied hospitals during New Year holiday and normal time period as timescales 1 and 2, respectively. Finally, the main objective of this assessment is to identify the clear path towards achieving sustainability excellence as an organizational goal.

Table 3 shows the opinions of patients as linguistic variables about the considered hospital assessment variables including social responsibility, hospital reputation, and service reception satisfaction as well as quality collected using a standard questionnaire based on the 5-point scale Likert as well as its fuzzy equivalent. Patients state their opinions separately for each considered assessment period. The uncertainty of the announced opinions is handled by the related interval type-2 fuzzy numbers. Finally, the lower and upper bounds of each research variable under uncertainty, handled by fuzzy set theory, are determined based on the patients' opinions (see Table 4).

The values of the policy-making and hospital waste as the other variables of the model are not determined based on the patients' opinions. To assess values of these variables, they are determined through consulting experts as a consequence of lack of relevant data and the need to assess the relevant documents at the Planning and Standard Department of the Ministry of Health and Medical Education in Iran. Table 5 shows the values of the lower and upper bounds of the policymakers and hospital waste variables. Levels of hospital waste production did not significantly vary during the considered time periods for efficiency assessment. Therefore, their related values are set equivalent in the considered time periods in terms of experts' opinions at the Iran Ministry of Health and Medical Education. Detailed required information about 11 hospitals, which are located in the selected province of Iran, is collected and the proposed efficiency assessment model is run using GAMS 23.4.

Obtained results indicate that Hos 7 has the greatest efficiency based on the considered network during the assessment timescales. Hos 1 and Hos 11 are ranked second and third, respectively, in terms of total efficiency measure, while Hos 10 holds the last place in the total efficiency ranking. A similar investigation

Table 3. Linguistic variable representation by interval type-2 fuzzy number.

\begin{tabular}{|c|c|}
\hline Linguistic variable & $\begin{array}{l}\text { Equivalent interval type-2 fuzzy number } \\
\left(\text { i.e. }\left(\left(\boldsymbol{a}_{1}^{U}, \boldsymbol{a}_{2}^{U}, \boldsymbol{a}_{3}^{U}, \boldsymbol{a}_{4}^{U} ; \boldsymbol{H}_{1}\left(A^{U}\right), \boldsymbol{H}_{2}\left(A^{U}\right)\right),\left(\boldsymbol{a}_{1}^{L}, \boldsymbol{a}_{2}^{L}, \boldsymbol{a}_{3}^{L}, \boldsymbol{a}_{4}^{L} ; \boldsymbol{H}_{1}\left(A^{L}\right), \boldsymbol{H}_{2}\left(A^{L}\right)\right)\right)\right)\end{array}$ \\
\hline Strongly agree & $(0.8,0.9,0.9,1: 1,1),(0.85,0.9,0.9,0.95: 0.9,0.9)$ \\
\hline Agree & $(0.6,0.7,0.7,0.8: 1,1),(0.65,0.7,0.7,0.75: 0.9,0.9)$ \\
\hline Undecided & $(0.4,0.5,0.5,0.6: 1,1),(0.45,0.5,0.5,0.55: 0.9,0.9)$ \\
\hline Disagree & $(0.2,0.3,0.3,0.4: 1,1),(0.25,0.3,0.3,0.35: 0.9,0.9)$ \\
\hline Strongly disagree & $(0,0.1,0.1,0.1: 1,1),(0,0.1,0.1,0.05: 0.9,0.9)$ \\
\hline
\end{tabular}


Table 4. Bounds of the fuzzy variables of the efficiency assessment based on the patients' opinions.

\begin{tabular}{|c|c|c|c|c|c|c|c|c|c|c|c|c|c|c|c|c|}
\hline \multirow{3}{*}{ Hospitals } & \multicolumn{4}{|c|}{ Hospital reputation } & \multicolumn{4}{|c|}{ Patients' satisfaction } & \multicolumn{4}{|c|}{ Service quality } & \multicolumn{4}{|c|}{ Social responsibility } \\
\hline & \multicolumn{2}{|c|}{ Timescale 1} & \multicolumn{2}{|c|}{ Timescale 2} & \multicolumn{2}{|c|}{ Timescale 1} & \multicolumn{2}{|c|}{ Timescale 2} & \multicolumn{2}{|c|}{ Timescale 1} & \multicolumn{2}{|c|}{ Timescale 2} & \multicolumn{2}{|c|}{ Timescale 1} & \multicolumn{2}{|c|}{ Timescale 2} \\
\hline & LB & UB & LB & UB & LB & UB & LB & UB & LB & UB & LB & UB & LB & UB & LB & UB \\
\hline Hos 1 & 0.316 & 0.370 & 0.160 & 0.175 & 0.251 & 0.313 & 0.155 & 0.169 & 0.303 & 0.360 & 0.145 & 0.162 & 0.212 & 0.366 & 0.135 & 0.147 \\
\hline Hos 2 & 0.402 & 0.431 & 0.422 & 0.453 & 0.423 & 0.450 & 0.424 & 0.463 & 0.405 & 0.438 & 0.393 & 0.431 & 0.401 & 0.434 & 0.405 & 0.444 \\
\hline Hos 3 & 0.231 & 0.257 & 0.226 & 0.247 & 0.194 & 0.219 & 0.182 & 0.201 & 0.232 & 0.264 & 0.209 & 0.237 & 0.217 & 0.237 & 0.202 & 0.223 \\
\hline Hos 4 & 0.187 & 0.202 & 0.234 & 0.267 & 0.199 & 0.224 & 0.220 & 0.231 & 0.168 & 0.180 & 0.227 & 0.254 & 0.163 & 0.180 & 0.201 & 0.221 \\
\hline Hos 5 & 0.121 & 0.135 & 0.194 & 0.219 & 0.106 & 0.120 & 0.183 & 0.206 & 0.112 & 0.138 & 0.201 & 0.224 & 0.107 & 0.123 & 0.198 & 0.220 \\
\hline Hos 6 & 0.362 & 0.396 & 0.431 & 0.468 & 0.304 & 0.331 & 0.396 & 0.432 & 0.289 & 0.315 & 0.363 & 0.400 & 0.299 & 0.327 & 0.432 & 0.474 \\
\hline Hos 7 & 0.409 & 0.441 & 0.381 & 0.429 & 0.327 & 0.362 & 0.345 & 0.384 & 0.340 & 0.367 & 0.377 & 0.419 & 0.395 & 0.439 & 0.404 & 0.434 \\
\hline Hos 8 & 0.427 & 0.472 & 0.380 & 0.431 & 0.363 & 0.409 & 0.322 & 0.363 & 0.433 & 0.475 & 0.401 & 0.446 & 0.452 & 0.497 & 0.401 & 0.450 \\
\hline Hos 9 & 0.468 & 0.518 & 0.418 & 0.452 & 0.335 & 0.382 & 0.312 & 0.348 & 0.476 & 0.515 & 0.402 & 0.455 & 0.503 & 0.550 & 0.421 & 0.464 \\
\hline Hos 10 & 0.447 & 0.488 & 0.399 & 0.450 & 0.311 & 0.352 & 0.268 & 0.298 & 0.455 & 0.488 & 0.398 & 0.486 & 0.457 & 0.519 & 0.403 & 0.441 \\
\hline Hos 11 & 0.388 & 0.426 & 0.442 & 0.480 & 0.275 & 0.306 & 0.239 & 0.334 & 0.373 & 0.412 & 0.421 & 0.477 & 0.373 & 0.423 & 0.441 & 0.490 \\
\hline
\end{tabular}

Table 5. Bounds of the fuzzy variables of the efficiency assessment through consulting experts.

\begin{tabular}{cccccccccc}
\hline & \multicolumn{3}{c}{ Hospital reputation } & \multicolumn{3}{c}{ Patients' satisfaction } \\
\cline { 2 - 9 } & Timescale 1 & \multicolumn{2}{c}{ Timescale 2 } & Timescale 1 & \multicolumn{2}{c}{ Timescale 2 } \\
\cline { 2 - 9 } Hospitals & LB & UB & LB & UB & LB & UB & LB & UB \\
\hline Hos 1 & 0.161 & 0.177 & 0.160 & 0.172 & 0.555 & 0.604 & 0.161 & 0.177 \\
Hos 2 & 0.084 & 0.093 & 0.088 & 0.094 & 0.502 & 0.551 & 0.084 & 0.093 \\
Hos 3 & 0.070 & 0.077 & 0.073 & 0.080 & 0.501 & 0.552 & 0.070 & 0.077 \\
Hos 4 & 0.038 & 0.043 & 0.042 & 0.045 & 0.512 & 0.550 & 0.038 & 0.043 \\
Hos 5 & 0.029 & 0.031 & 0.028 & 0.030 & 0.547 & 0.598 & 0.029 & 0.031 \\
Hos 6 & 0.016 & 0.018 & 0.015 & 0.016 & 0.464 & 0.527 & 0.016 & 0.018 \\
Hos 7 & 0.012 & 0.013 & 0.013 & 0.014 & 0.489 & 0.544 & 0.012 & 0.013 \\
\hline
\end{tabular}

could be done for each node of the considered network including hospital, community, and patients. For instance, Hos 7 is ranked first in total efficiency on two time scales regarding network variables associated with the hospital node, while it is ranked first on each of Timescales 1 and 2 separately (see Table 6). Obtained results indicate the condition of the sustainability of the considered healthcare network including 11 hospitals. Each hospital can define the desired and specific preferences in the strategic planning and use the advantage of the best practices of the efficient hospitals. It should be noted that particular management circumstances such as accessibility of human resources, healthcare status of each region, resource management, and cultural development types must be considered in applying benchmarking process. Through detailed efficiency assessments, more useful managerial, economic, and political interpretations are proposed. Figure 4 presents the averages of total efficiencies of 11 hospitals considering various nodes. The community node and the patient node have the lowest and greatest means of efficiency values by comparison, separately.

\subsection{Sensitivity analysis}

Figure 5 presents the total number of efficient hospitals among all the assessed hospitals in terms of the three considered nodes including hospital, community, and patient. For instance, in 7 of total 11 hospitals, the patient node is of higher efficiency than hospital and community nodes. In addition, the efficiency of the hospital node is greater than the other considered nodes in 4 hospitals. Finally, the efficiency of the community node is greater than those of hospital and patient nodes only for 4 governmental hospitals, which are located in each city of the considered province. These findings strictly indicate that the major issue of Iran 
Table 6. Efficiencies of the investigated hospitals.

\begin{tabular}{|c|c|c|c|c|c|c|c|c|c|c|c|c|c|c|c|c|}
\hline \multirow[b]{2}{*}{ Hos. ${ }^{a}$} & \multirow[b]{2}{*}{$\begin{array}{c}\text { Total } \\
\text { efficiency }\end{array}$} & \multicolumn{5}{|c|}{ Hospital node efficiencies } & \multicolumn{4}{|c|}{ Community node efficiencies } & \multicolumn{6}{|c|}{ Patients node efficiencies } \\
\hline & & R Total T. & & T.1 & R. & T.2 & R. Total T. & T.1 & R. & T.2 & R. Total T. & R. & T.1 & R. & T.2 & R. \\
\hline Hos 1 & {$[0.56,0.68]$} & $2 \quad[0.73,1]$ & 4[ & {$[0.27,0.43]$} & ] 6 & {$[0.95,1]$} & $2 \quad[0.54,1]$ & $1 \quad[0.86,1]$ & 1 & {$[0.77,1]$} & $3 \quad[0.72,1]$ & 1[ & {$[0.55,0.64]$} & & $0.74,0.81]$ & 3 \\
\hline Hos 2 & {$[0.50,0.56]$} & $6[0.48,0.69]$ & 6[ & {$[0.45,0.48]$} & 5 & {$[0.41,0.48]$} & $4[0.35,0.53]$ & $7[0.44,0.79]$ & 6 & {$[0.65,0.89]$} & $7[0.83,0.87]$ & 2[ & {$[0.86,0.87]$} & & $0.83,0.85]$ & 1 \\
\hline Hos 3 & {$[0.48,0.49]$} & $10[0.22,0.45]$ & 10 & {$[0.2,0.21]$} & 9 & {$[0.22,0.24]$} & $8[0.32,0.37]$ & $10[0.43,0.51]$ & 9 & {$[0.57,0.67]$} & $10[0.62,0.64]$ & & {$[0.63,0.65]$} & & $0.59,0.61]$ & 17 \\
\hline Hos 4 & {$[0.48,0.55]$} & $9[0.41,0.67]$ & 7[ & {$[0.35,0.38]$} & 7 & {$[0.39,0.46]$} & $5[0.33,0.47]$ & $9[0.33,0.55]$ & & {$[0.65,0.82]$} & $8[0.71,0.73]$ & 4[ & {$[0.69,0.71]$} & & $0.71,0.73]$ & 4 \\
\hline Hos 5 & {$[0.54,0.60]$} & $4 \quad[0.79,1]$ & 2 & {$[0.96,1]$} & 1 & {$[0.96,1]$} & $1[0.46,0.63]$ & $5 \quad[0.72,1]$ & 3 & {$[0.67,0.97]$} & $6[0.67,0.81]$ & 3[ & {$[0.58,0.67]$} & & $0.66,0.87]$ & 5 \\
\hline Hos 6 & {$[0.50,0.55]$} & $7[0.26,0.65]$ & 9[ & {$[0.26,0.28]$} & 8 & {$[0.22,0.23]$} & $7[0.35,0.54]$ & $6[0.40,0.74]$ & 7 & {$[0.60,0.84]$} & $9[0.63,0.65]$ & 6[ & {$[0.65,0.66]$} & & $0.60,0.61]$ & 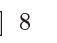 \\
\hline Hos 7 & {$[0.56,0.70]$} & $1 \quad[0.85,1]$ & 1 & {$[0.95,1]$} & 2 & {$[0.95,1]$} & $2 \quad[0.53,1]$ & $2 \quad[0.79,1]$ & 2 & {$[0.87,1]$} & $1 \quad[0.72,1]$ & 1[ & {$[0.68,0.78]$} & & $0.78,0.86]$ & \\
\hline Hos 8 & {$[0.51,0.61]$} & $5[0.29,0.66]$ & 8[ & {$[0.26,0.28]$} & ] 8 & {$[0.28,0.30]$} & $\begin{array}{ll}6 & {[0.37,1]}\end{array}$ & $4 \quad[0.47,1]$ & 5 & {$[0.63,1]$} & $5[0.59,0.61]$ & 8[ & {$[0.58,0.63]$} & & $0.59,0.60]$ & 10 \\
\hline Hos 9 & {$[0.45,0.59]$} & $8 \quad[0.79,1]$ & 2 & {$[0.85,1]$} & 3 & {$[0.96,1]$} & $1[0.18,0.63]$ & $8[0.24,0.38]$ & 11 & {$[0.72,1]$} & $4[0.52,0.74]$ & 7 & {$[0.68,0.81]$} & & $0.57,0.63]$ & 9 \\
\hline Hos 10 & {$[0.48,0.52]$} & $11 \quad[0.76,1]$ & 3 & {$[0.95,1]$} & 2 & {$[0.96,1]$} & $1[0.31,0.40]$ & $11[0.48,0.66]$ & 8 & {$[0.57,0.70]$} & $11[0.38,0.56]$ & 9[ & {$[0.60,0.68]$} & & $0.33,0.38]$ & \\
\hline Hos 11 & {$[0.53,0.68]$} & $3[0.63,0.79]$ & 5 & {$[0.63,1]$} & 4 & {$[0.47,0.47]$} & $\begin{array}{ll}3 & {[0.46,1]}\end{array}$ & $3 \quad[0.70,1]$ & 4 & {$[0.78,1]$} & $2[0.67,0.81]$ & 3[ & {$[0.66,0.67]$} & & $0.70,0.74]$ & 6 \\
\hline
\end{tabular}

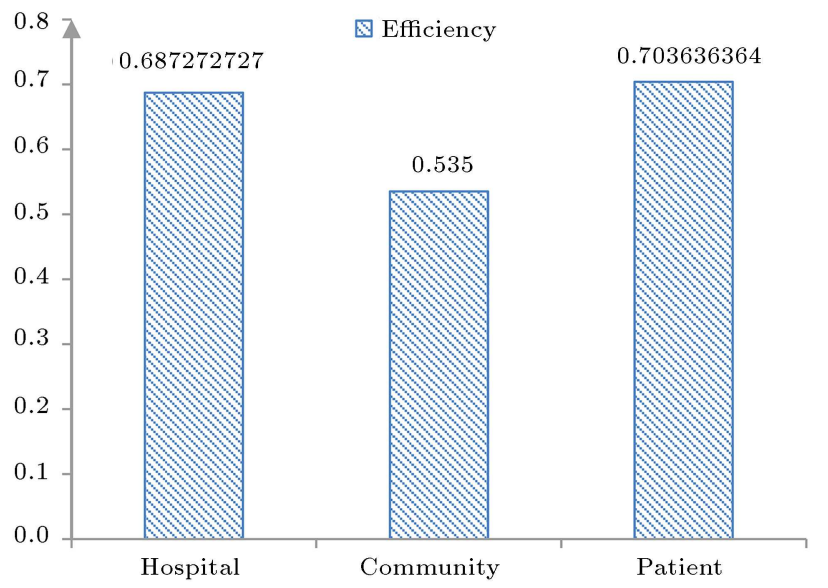

Figure 4. The means of total efficiencies of hospitals.

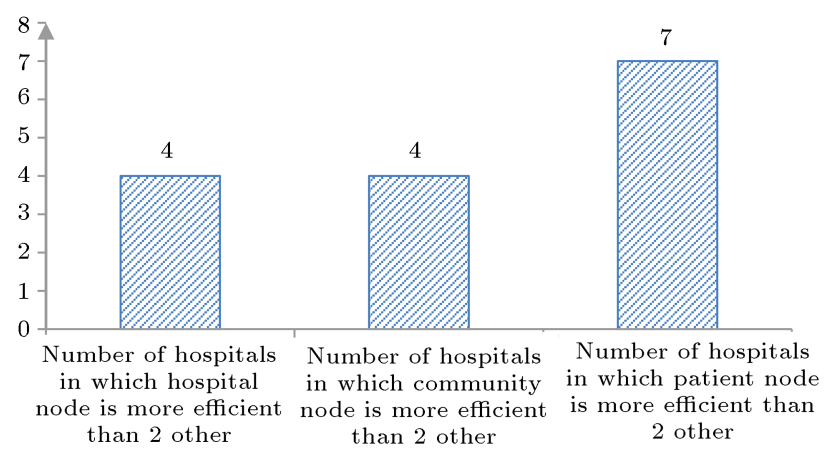

Figure 5. Evaluation of the considered network nodes compared to each other.

hospital efficiency management depends on existing relationships with community node and associated liability, besides hospital management issues. European commission [55] indicates the importance of considering community dimension in hospital efficiency assessment and development of patient-reported outcome measures which offer a promising opportunity to improve outcome measurement for a comprehensive assessment framework.

Based on the obtained results, studied hospitals have been unsuccessful in meeting their desired social responsibilities. In addition, they have not been able to manage their service capacity such that a good reputation for organization is established and the waste of organizational resource and waste production are reduced, leading to environmental pollution. Undesirable level of hospital social responsibility in Iran and its potential impacts on total efficiency are also given in other studies and have been confirmed in previous studies [56-58]. To tackle this challenge, defining appropriate organizational visions related to hospital social responsibility as well as reducing the number of environmental pollutions besides setting comprehensive strategies and coordinated tactical planning with a specific schedule can be helpful in achieving the considered goals. The development policies adopted by hospitals under consideration should be offered to the organization's stakeholders and appropriate communication channels should be managed with the aim of making them able to propose their cooperative statements. These initiatives lead organizational stakeholders to a better recognition that hospitals should believe in their responsibilities with respect to the society and attend to the necessity of efficient waste management in order to reduce the resource waste and environmental pollutions as a key issue while considering the opinions of other stakeholders. To tackle this challenge, using best practice benchmarking of hospitals' experiences and formulating an effective branding strategy could facilitate achieving sustainable success for corporates. The existence of a specific office at each hospital equipped with resolute and trained hospital personnel responsible for conserving the local kinds and tracking the decreasing trend of waste production contributes to the realization of hospital responsibility for environmental issues. Furthermore, adoption of a comprehensive plan for healthcare service-providing systems throughout the day leads to waste and pollution levels such as hospital waste, which is produced in the diagnosis, treatment, 
and immunization processes. Among the considered variables related to the hospital node given in Figure 2, non-healthcare income potentially plays a crucial role in making hospitals more efficient. This opportunity has also been confirmed by experts. The addition of new service lines such as educational, consulting, and research services as well as exploitation of other opportunities like the number of business partners are some of the best practices for increasing hospital profitability. In addition, other factors such as budgeting method and various approaches to policy-making would be used so that the social and environmental responsibilities of hospitals as well as the quality-of-service consistency for community and patients' demands can be simultaneously enhanced. Obtained results indicate that the average efficiency of hospitals regarding patient node is greater than the efficiencies of community and hospital nodes (Figure 2). One of the main reasons for the occurrence of this phenomenon is that the majority of the studied hospitals are local facilities with patients who are not well aware of the updated health service standards. Nevertheless, people in the community could be informed of hospitals' performance through available media, especially social media, and they evaluate the realized performance in comparison to other hospitals in terms of high standards. Therefore, hospital managers should continuously attempt to enhance the quality of healthcare services. Different timescales could be considered to assess the efficiency of the considered network during the planning horizon. Figure 6 presents the comparison among network nodes including hospital, community, and patients in terms of the considered timescale.

In view of the hospital node on time scale 1, 27.2\% of the total 11 hospitals performed better. New Year holidays in Iran, representing timescale 1 here, is one of the major travelling seasons with the highest number of holidaymakers along with many road accidents.

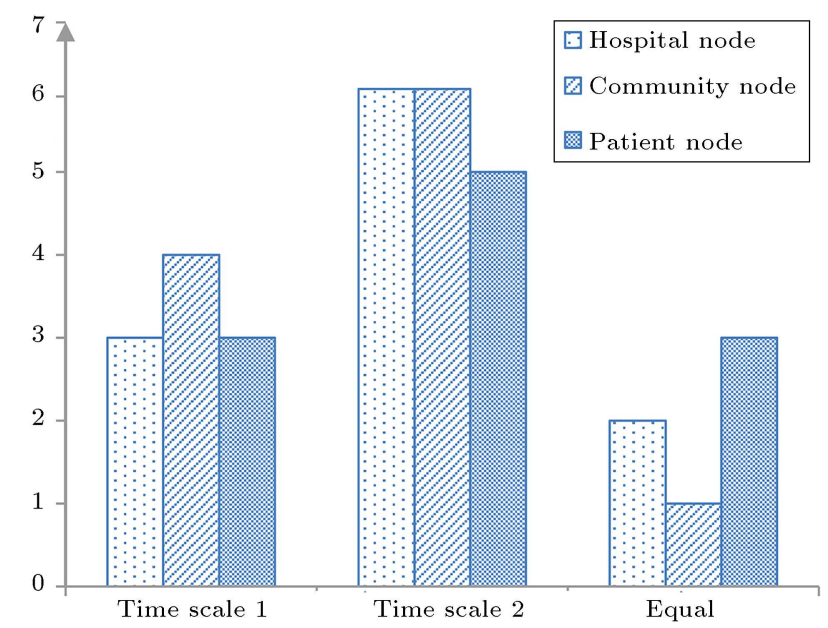

Figure 6. Performance comparison in terms of the considered timescales.
Time scale 2 is considered as an ordinary timescale during the year. In addition, $54.5 \%$ of hospitals had a better performance on time scale 2 . Finally, $18.18 \%$ of hospitals were equal in performance on two time scales 1 and 2. A large number of the injured during the vacation parallel to a small number of employees cause high workload during the holidays. This condition reduces hospitals' performance in providing health services. The same results are made considering the nodes of community and patient. The reputation of the hospital is reduced by increasing the total workload during the bounded period. Finally, the performance of most of the hospitals is better on time scale 2. Hospital managers could reduce the gap associated with the total efficiency of the organization by taking various measures and considering improvement programs during the New Year vacation. These initiatives could increase the satisfaction of stakeholder community.

\subsection{Managerial insights}

The obtained key results are investigated in depth to provide the following practical managerial insights to ensure efficient sustainable healthcare network management:

- By applying detailed efficiency assessments based on interrelated roles and multi-time scales, viable managerial, economic, and political interpretations could be presented as a guide for complex healthcare network management by extensive interactions with its external environment;

- Social responsibility has become increasingly important to healthcare system planners who seek investments that are not only profitable but also conducive to the welfare of society and the environment. Hospitals as key players in the healthcare system need to focus more on enhancing social responsibility by managing their service capacities in a way that a good reputation for organizations can be established. In addition, waste minimization and resources usage optimization using zero waste principles should be adopted to reduce environmental pollutions aligned with the organization vision goals over the planning period;

- Appropriate collaboration through proper communication channels with the organization's stakeholders should be planned so that they can contribute their cooperative statements. Therefore, what stakeholders hold dear is that hospitals should solidify their responsibilities with respect to the society and attend to the necessity of efficient waste management in order to reduce the resource waste and environmental pollutions as a key issue while considering the opinions of other stakeholders. Waste management in key processes of diagnosis, treatment, and immunization involves prevention, 
recycling, reuse, and recovery which relieves the burden on managing landfills, conserves natural resources, and saves energy. These initiatives should be comprehensively planed, done, checked, and acted by a specific center defined within the organizational structure;

- Based on the considered three dimensions of hospital, community, and patients in the proposed assessment network, efforts such as adding new service lines and exploiting other opportunities like the extensive network of business partners are some of the best practices for boosting growth and profitability of the hospital node. In recent years, educational, consulting, and research services have attracted the attention of hospital managers as new service lines;

- Applying accurate budgeting method and appropriate approaches to policy-making is important to simultaneously improve the social and environmental responsibilities of hospitals as well as the qualityof-service consistency for the community and patients. Through these management efforts, rapid changes in the decision-making environment should be made including changes in patients' expectations. Improving hospital performance using developed standards under the supervision of the governmental and non-governmental organizations is strictly recommended. Increase in patients' awareness about the updated health service standards acts as an effective lever for making changes to improve the efficiency and service quality of the hospitals;

- Making an appropriate balance between demand of healthcare services and capacity of service providing has a significant impact on hospital performance. High workload on hospital employees during particular work periods like holidays and pandemics such as COVID19 attenuates hospital reputation and its total performance. Therefore, considering backup resources including reserved specialized manpower can improve the balance between demand of healthcare services and service capacity.

\section{Conclusion}

In this study, a comprehensive investigation of the effective performance of hospitals, which play an important role in the healthcare system, was done with emphasis on sustainable development principles. For this purpose, the uncertainty surrounding the assessment variables is handled by the dynamic network Data Envelopment Analysis (DEA), which incorporated the interval type-2 fuzzy Decision Making Trial and Evaluation Laboratory (DEMATEL) and best-worst method based on experts' opinions. By applying the proposed efficiency assessment model, hospital managers can comprehensively analyze the present situation and adopt an appropriate strategic plan as well as corrective actions. A viable sustainability assessment needs multi-perspective analysis to facilitate key management concerns in terms of environmental, social, and economic causes and their main direct and indirect consequences of the inequities. This study promotes awareness on how the organizational activities of the hospitals should be regarded from various viewpoints to ensure consistency with each other and to make the entire hospital a sustainable entity. According to obtained results, the studied hospitals were ranked in terms of total efficiency by considering the sustainability-related variables involved. In light of the sustainability concepts, there is a secure and successful path for organizational growth in the future. Despite the initial expectations of efficiency assessment, the main current problem as a key improvement opportunity for most of the studied hospitals is associated with their relationships with community pillar. Therefore, healthcare policymakers and hospital administrators should adopt precise strategies to keep their sustainability levels aligned with the key aspects of the community. In addition, they should conduct comprehensive plans with the aim of defining appropriate solutions with respect to social and environmental responsibilities. Future studies should consider service quality, which is an important factor in healthcare service provision, in the hospital efficiency assessment process. In addition, other effective factors including working conditions of employees in the hospitality sector, hygiene, turnover, and other related issues in the community node could increase the effectiveness of the assessment process.

\section{References}

1. Lorenzoni, L., Belloni, A., and Sassi, F. "Health-care expenditure and health policy in the USA versus other high-spending OECD countries", Lancet, 384, pp. 8392 (2014).

2. Green, L.V., Savin, S., and Lu, Y. "Primary care physician shortages could be eliminated through use of teams, non-physicians, and electronic communication", Health Aff, 32(1), pp. 11-19 (2013).

3. Carter, C.R. and Rogers, D.S. "A framework of sustainable supply chain management: Moving toward new theory", International Journal of Physical Distribution \& Logistics Management, 38(5), pp. 360-387 (2008).

4. Lee, C.K.M. and Lam, J.S.L. "Managing reverse logistics to enhance sustainability of industrial marketing", Industrial Marketing Management, 41(4), pp. 589-598 (2012).

5. Nidumolu, R., Prahalad, C.K., Rangaswami, M.R., Innovative and sustainable healthcare management strategies for growth, United Kingdom (2012). 
6. Buck, D. and Gregory, S., Improving the Public's Health, The Kings Funds, pp. 1-60 (2013).

7. Bloom, D.E. and Canning, D. "Population health and economic growth", Commission on Growth and Development Working, 24, World Bank, Washington, DC, World Bank (2008).

8. Weisz, U., Haas, W., Pelikan, J.M., et al. "Sustainable hospitals: A socio-ecological approach", GAIA, 20(3), pp. 191-198 (2011).

9. Health Research \& Educational Trust, Environmental Sustainability in Hospitals: The Value of Efficiency, Chicago, IL: Health Research \& Educational Trust (2014).

10. Lim, S. and Zhu, J. "A note on two-stage network DEA model: Frontier projection and duality", Eur. J. Oper. Res, 248(1), pp. 342-346 (2016).

11. Oukil, A. "Ranking via composite weighting schemes under A DEA cross-evaluation framework", Computers \& Industrial Engineering, 117, pp. 217-224 (2018).

12. Ghorashi, N., Rad, A., and Eslami, M. "The study on factors of health economics and economic growth in Iran", Journal of Community Health Research, 2(3), pp. 208-219 (2013).

13. Weisz, U., Haas, W., Pelikan, J.M., et al. "Sustainable hospitals: A socio-ecological approach", GAIAEcological Perspectives for Science and Society, 20(3), pp. 191-198 (2011).

14. CABE, Future Health: Sustainable Places for Health and Well-Being (2009).

15. Cantor, V.J.M. and Poh, K.L. "Integrated analysis of healthcare efficiency: A systematic review", Journal of Medical Systems, 42(8), pp. 1-23 (2018).

16. Ortíz-Barrios, M.A., Escorcia-Caballero, J.P., Sánchez-Sánchez, F., et al. "Efficiency analysis of integrated public hospital networks in outpatient internal medicine", Journal of Medical Systems, 41, pp. 163-181 (2017).

17. Cook, W.D., Liang, L., and Zhu, J. "Measuring performance of two-stage network structures by DEA: A review and future perspective", Omega, 38, pp. 423430 (2010).

18. Cook, W.D., Tone, K., and Zhu, J. "Data envelopment analysis: Prior to choosing a model", Omega, 44, pp. 1-4 (2014).

19. Bhat, R., Verma, B.B., and Reuben, E. "Hospital efficiency: An empirical analysis of district hospitals and grant in aid hospitals in Gujarat", Journal of Health Management, 3(2), pp. 167-197 (2001).

20. Ozgen, H. and Ozcan, Y. "Longitudinal analysis of efficiency in multiple output dialyses", Health Care Management Sciences, 7, pp. 253-261 (2004).

21. Kontodimopoulos, N. and Niakas, D. "Efficiency measurement of hem dialysis units in Greece with data envelopment analysis", Health Policy, 71, pp. 195-204 (2005).
22. Ng, Y.C. "The productive efficiency of Chinese hospitals", China Economic Review, 22(3), pp. 428-439 (2011).

23. Ng, Y.C. "The productive efficiency of the health care sector of China", Rev. Reg. Stud, 38(3), pp. 381-393 (2008).

24. Li, H., Dong, S., and Liu, T. "Relative efficiency and productivity: A preliminary Eexploration of public hospitals in Beijing", China, BMC Health Serv. Res, 14(1), pp. 158-169 (2014).

25. Du, J., Wang, J., Chen, Y., et al. "Incorporating health outcomes in Pennsylvania hospital efficiency: An additive super-efficiency DEA approach", Annals of Operations Research, 221(1), pp. 161-172 (2014).

26. Feng, S., Shi, L., Zeng, J., et al. "Comparison of primary care experiences in village clinics with different ownership models in Guangdong Province", China, PLoS ONE, 12(1), pp. 1-14 (2017).

27. Arya, A. and Yadav, S.P. "Development of intuitionistic fuzzy super-efficiency slack based measure with an application to health sector", Computers \& Industrial Engineering, 115, pp. 368-380 (2018).

28. Hasani, A. and Zegordi, S.H. "A robust competitive global supply chain network design under disruption: The case of medical device industry", International Journal of Industrial Engineering \& Production Research, 26(1), pp. 63-84 (2015).

29. Liang, Q. and Mendel, J.M. "Interval type-2 fuzzy logic systems: theory and design", IEEE Transactions on Fuzzy Systems, 8(5), pp. 535-550 (2000).

30. Castillo, O. and Melin, P. "A review on interval type-2 fuzzy logic applications in intelligent control", Information Sciences, 279, pp. 615-631 (2014).

31. Withanachchi, N., Uchida, Y., Nanayakkara, S., et al. "Resource allocation in public hospitals: Is it effective?", Health Policy (New York), 80(2), pp. 308313 (2007).

32. Korhonen, P. and Syrjänen, M. "Resource allocation based on efficiency analysis", Management Science, 50(8), pp. 1134-1144 (2004).

33. Luscombe, R. and Kozan, E. "Dynamic resource allocation to improve emergency department efficiency in real time", European Journal of Operational Research, 255(2), pp. 593-603 (2016).

34. Lozano, S. and Villa, G. "Centralized resource allocation using data envelopment analysis", Journal of Productivity Analysis, 22(1-2), pp. 143-161 (2004).

35. Khushalani, J. and Ozcan, Y.A. "Are hospitals producing quality care efficiently? An analysis using dynamic network data envelopment analysis (DEA)", SocioEconomic Planning Sciences, 60, pp. 15-23 (2017).

36. Omrani, H., Shafaat, K., and Emrouznejad, A. "An integrated fuzzy clustering cooperative game data envelopment analysis model with application in hospital efficiency", Expert Systems with Applications, 114, pp. 615-628 (2018). 
37. Motevali Haghighi, S. and Torabi, S.A. "A novel mixed sustainability-resilience framework for evaluating hospital information systems", International Journal of Medical Informatics, 118, pp. 16-28 (2018).

38. Zare, H., Tavana, M., and Mardani, A. "Hybrid data envelopment analysis and game theory model for performance measurement in healthcare", Health Care Management Science, 22, pp. 475-488 (2019).

39. Rouyendegh, B.D., Oztekin, A., and Ekong, J. "Measuring the efficiency of hospitals: A fully-ranking DEAFAHP approach", Annals of Operations Research, 278, pp. 361-378 (2019).

40. Ghahremanloo, M., Hasani, A., Amiri, M., et al. "A novel DEA model for hospital performance evaluation based on the measurement of efficiency, effectiveness, and productivity", Engineering Management in Production and Services, 12(1), pp. 7-19 (2020).

41. Bogetoft, P., Fare, R., Grosskopf, S., et al. "Dynamic network DEA: An illustration", Journal of the Operations Research Society of Japan, 52(2), pp. 147-162 (2009).

42. Tone, K. and Tsutsui, M. "Network DEA: A slacksbased measure approach", European Journal of Operational Research, 197, pp. 243-252 (2009).

43. Herrera-Restrepo, O., Triantis, K., Trainor, J., et al. "A multi-perspective dynamic network performance efficiency measurement of an evacuation: A dynamic network-DEA approach", Omega, 60, pp. 4559 (2016).

44. Hasseldine, J., Salama, A.I., and Toms, J.S. "Quantity versus quality: The impact of environmental disclosures on the reputations Of UK places", Br. Account. Rev, 37(2), pp. 231-248 (2005).

45. Olfat, L., Amiri, M., Soufi, J.B., et al. "A dynamic network efficiency measurement of airports performance considering sustainable development concept: A fuzzy dynamic network-DEA approach", In Journal of Air Transport Management, 57, pp. 272-290 (2016).

46. Beder, S. "Environmentalists help manage corporate reputation: Changing perceptions not behavior", Ecopolitics, 1(4), pp. 60-72 (2002).

47. Wu, D.R. and Mendel, J.M. "Aggregation using the linguistic weighted average and interval type-2 fuzzy sets", IEEE Trans. Fuzzy Syst, 15, pp. 1145-1161 (2007).

48. Hu, J., Zhang, Y., Chen, X., et al. "Multi-criteria decision making method based on possibility degree of interval type-2 fuzzy number", Knowledge-Based Systems, 43, pp. 21-29 (2013).

49. Abdullah, L. and Zulkifli, N. "Integration of fuzzy AHP and interval type-2 fuzzy DEMATEL: An application to human resource management", Expert Systems with Applications, 42(9), pp. 4397-4409 (2015).

50. Li, G.D., Yamaguchi, D., and Nagai, M. "A grey-based decision making approach to the supplier selection problem", Mathematical and Computer Modeling, 46, pp. 573-581 (2007).
51. Shieh, J.I., Wu, H.H., and Huang, K.K. "A DEMATEL method in identifying key success factors of hospital service quality", Knowledge-Based Systems, 23, pp. 277-282 (2010).

52. Rezaei, J. "Best-worst multi-criteria decision-making method", Omega, 53, pp. 49-57 (2015).

53. Rezaei, J. "Best-worst multi-criteria decision-making method: Some properties and a linear model", Omega, 64, pp. 126-130 (2016).

54. Opricovic, S. and Tzeng, G.H. "Defuzzification within a multi-criteria decision model", International Journal of Uncertainty, Fuzziness and Knowledge-based Systems, 11, pp. 635-652 (2003).

55. Expert Group on Health System Performance Assessment. "Tools and methodologies to assess the efficiency of health care services in Europe" (Report NO. EW01-19-365-EN-N), European Commission (2019).

56. Keyvanara, M. and Sajadi, H. "Social responsibility of the hospitals in Isfahan City, Iran: Results from a cross-sectional survey", International Journal of Health Policy and Management, 4(8), pp. 517-522 (2015).

57. Griffiths J. "Environmental sustainability in the national health service in England", Public Health, 120, pp. 609-612 (2006).

58. Tudor, T.L., Bannister, S., Butler, S., et al. "Can corporate social responsibility and environmental citizenship be employed in the effective management of waste?: Case studies from the National Health Service (NHS) in England and Wales Resources", Conservation and Recycling, 52, pp. 764-674 (2008).

\section{Appendix}

\section{Questionnaires}

Through the assessment process, some variable values are calculated based on standard questionnaire (see Figures A.1 and A.2 as well as Table A.1).

\begin{tabular}{|c|c|c|c|c|c|c|}
\hline \multirow{2}{*}{$\begin{array}{c}\text { Expert } \\
\text { number }\end{array}$} & \multirow{2}{*}{$\begin{array}{c}\text { Best } \\
\text { criteria }\end{array}$} & \multirow{2}{*}{$\begin{array}{c}\text { Worst } \\
\text { criteria }\end{array}$} & \multicolumn{4}{|c|}{ Assessment criteria } \\
\hline & & $\mathrm{C}_{1}$ & $\mathrm{C}_{2}$ & $\cdots$ & $\mathrm{C}_{\mathrm{n}}$ \\
\hline 1 & $\mathrm{C}_{\mathrm{B} 1}$ & & & & & \\
\hline 2 & & $\mathrm{C}_{\mathrm{w} 1}$ & & & & \\
\hline & $\mathrm{C}_{\mathrm{B} 2}$ & & & & & \\
\hline 3 & $\mathrm{C}_{\mathrm{B} 3}$ & & & & & \\
\hline & & $\mathrm{C}_{\mathrm{w} 3}$ & & & & \\
\hline$\vdots$ & $\vdots$ & $\vdots$ & $\vdots$ & $\vdots$ & $\vdots$ & $\vdots$ \\
\hline \multirow{2}{*}{$\mathrm{k}$} & $\mathrm{C}_{\mathrm{Bk}}$ & & & & & \\
\hline & & $\mathrm{C}_{\mathrm{wk}}$ & & & & \\
\hline
\end{tabular}

Figure A.1. BWM questionnaire template. 
Table A.1. Questions of the questionnaire presented to the patients.

\section{Hospital reputation}

- This hospital has a good reputation in comparison to other considered hospitals.

- Services at the hospital are done decently and in order.

- I believe that management and hospital personnel are always looking to improve the serving process.

- It is oblivious that how to overcome the need that arises in the future has been considered in I believe the hospital services planning.

- I believe that hospital management and personnel are always looking to meet the needs of patients.

\section{Hospital social responsibility}

- Various business functions at the hospital show that hospital management cares for creating as well as enhancing opportunities for revenue-earning and employment in the region.

- Played ceremonies, billboards or announcements on the hospital's website show that the management care about environmental preservation and sustainable development and the transferring of this culture among the public.

- Selling medical and non-medical suppliers needed by patients at the hospital (i.e., local suppliers have a higher priority) and it seems that management pays attention to transferring the culture of the region to the patients.

- Billboard or announcements that are available on the hospital website specify that the hospital cares about humanitarian activities as well as promoting public health and tries to promote this culture among the public.

- Using equipment and new technology shows that the hospital management seeks to reduce energy consumption and tries to protect environmental resources.

- Since things like trash bins for plastics or paper are available, it becomes clear that the separation of waste at the source is important in this hospital.

\section{Patients satisfaction}

- Carried sufficient attention to the seeds of patients in the process of providing services associated with healthcare, which cause my satisfaction. The use of hospital services makes me feel less anxiety during treatment.

- I am satisfied with the supplementary services at the hospital.

\section{Service quality}

- Provision of services is done magnificently and in a standard manner.

- The performance of the hospital and the delivery of services are just as already promised.

- If the service is not provided as promised, the reason is announced to patients with patience.

- Amenities to meet basic needs such as prayer rooms, toilets, and changing rooms for children or residents are accessible at the hospital.

- The state of cleanliness and hygiene in the entire hospital area is appropriate.

- Patients' statuses are considered in providing services and this matter is obvious from the presence of a feature.

- Public transport is available so that patients can easily use them to reach the main centers of the area.

- Taking advantage of online services for patients, through the use of Wi-Fi systems or café-net is possible to create opportunities to obtain information in the shortest possible time.

- Parking with sufficient capacity and with easy access to the area around the hospital is available.

- Necessary information about hospital services or ceremonies and special activities is announced through means such as websites or bulletin boards.

- The low-income strata of society have been considered in projects such as the construction of the dining and transport system from the hospital to other areas.

- The healthcare services formalities at the hospital are announced on the website or through means such as billboards to make patients able to have a more comfortable treatment experience.

- The service providers' behaviors at the hospital with patients are polite and with humility.

- Facing complaints and criticisms of the patients are done patiently, with empathy, and with enough time consumption. 


\begin{tabular}{|c|c|c|c|c|}
\hline & $\mathrm{C}_{1}$ & $\mathrm{C}_{2}$ & $\cdots$ & $\mathrm{C}_{\mathrm{n}}$ \\
\hline $\mathrm{C}_{1}$ & & & & \\
\hline $\mathrm{C}_{2}$ & & & & \\
\hline & & & & \\
$\vdots$ & & & & \\
\hline $\mathrm{C}_{\mathrm{n}}$ & & & & \\
\hline
\end{tabular}

Figure A.2. DEMATEL questionnaire template.

\section{Biographies}

Aliakbar Hasani is currently an Associate Professor of Industrial Engineering at Shahrood University of Technology, Iran. His current research interests include supply chain management, production planning and scheduling, multi-objective optimization problems, meta-heuristics, quality management, and productiv- ity. He has also published several papers in International Journals such as International Journal of Production Research, Transportation Research Part E, Journal of Cleaner Production, Computers \& Chemical Engineering, Socio-Economic Planning Sciences, Journal of Manufacturing Systems, Resources Policy, and Safety Science.

Hadi Mokhtari is currently an Associate Professor of Industrial Engineering at University of Kashan, Iran. His current research interests include the applications of operations research and artificial intelligence techniques to the areas of project scheduling, production scheduling, manufacturing supply chains, and engineering economic problems. He has also published several papers in International Journals such as Computers and Operations Research, International Journal of Production Research, Applied Soft Computing, Journal of Cleaner Production, Neurocomputing, International Journal of Advanced Manufacturing Technology, IEEE Transactions on Engineering Management, and Expert Systems with Applications. 